\title{
Transesophageal echocardiographic scoring for transcatheter aortic valve implantation: Impact of aortic cusp calcification on postoperative aortic regurgitation
}

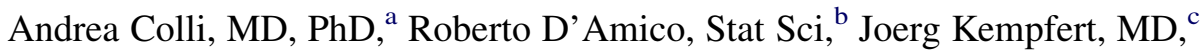 \\ Michael A. Borger, MD, PhD, ${ }^{\mathrm{c}}$ Friedrich W. Mohr, $\mathrm{MD}, \mathrm{PhD},{ }^{\mathrm{c}}$ and Thomas Walther, $\mathrm{MD}, \mathrm{PhD}^{\mathrm{c}}$
}

\begin{abstract}
Objective: Transcatheter aortic valve implantation is an emerging technique for the treatment of aortic valve stenosis in high-risk patients. Detailed knowledge of aortic root anatomy, including specific information on the extent of native cusp calcifications, is required. The aim of this study was to evaluate whether echocardiographic assessment of aortic stenosis using a calcification score is useful to predict outcomes of transcatheter aortic valve implantation in elderly high-risk patients.
\end{abstract}

Methods: Detailed preoperative digitalized transesophageal echocardiographic images were available from 103 patients treated by transapical transcatheter aortic valve implantation between February 2006 and February 2009. On the basis of a previously published study, an index score was developed to describe the extent of valve calcification ranging from 0 to 8 (normal to diffuse calcification).

\begin{abstract}
Results: The median age of patients was $82.2 \pm 5.9$ years. The mean logistic European System for Cardiac Operative Risk Evaluation was $33.0 \% \pm 16.3 \%$. Mild paravalvular leak was present in 43 patients $(42.2 \%)$, and a moderate paravalvular leak was observed in 5 patients $(4.9 \%)$. Severe regurgitation was not observed in any patient. Logistic regression analysis revealed that the transcatheter aortic valve implantation echocardiographic calcification score is associated with the presence of moderate paravalvular aortic regurgitation (odds ratio, 8.5; $95 \%$ confidence interval, $1.2-58.9 ; P=.0001$ ) and overall moderate aortic regurgitation (odds ratio, 3.6; 95\% confidence interval, $1.2-10.4 ; P=.0006)$.
\end{abstract}

Conclusions: Transesophageal echocardiography demonstrates detailed anatomic information of the calcification patterns of the aortic valve and root and thus plays an important role in the screening of patients undergoing transcatheter aortic valve implantation. The transcatheter aortic valve implantation echocardiographic calcification score allowed prediction of the risk of postoperative paravalvular and overall aortic regurgitation. ( $\mathrm{J}$ Thorac Cardiovasc Surg 2011;142:1229-35)

Aortic stenosis (AS) is the most frequent acquired heart valve lesion in the Western world. Therapeutic intervention is based on standardized guidelines, which have resulted in excellent outcomes using conventional surgical valve replacement, in young patients with a relatively low-risk profile $e^{1-3}$ and even in octogenarians. ${ }^{4-7}$ Transcatheter aortic valve implantation (TAVI) is a relatively new therapeutic option to treat elderly high-risk patients with AS, and it may evolve as an alternative

\footnotetext{
From the Department of Cardiac Surgery, ${ }^{\mathrm{a}}$ Hospital Universitari Germans Trias i Pujol, Badalona, Barcelona, Spain; Department of Oncology and Hematology, ${ }^{\mathrm{b}}$ University of Modena and Reggio Emilia, Modena, Italy; and Department of Cardiac Surgery, ${ }^{c}$ Heartcenter, University of Leipzig, Leipzig, Germany.

Andrea Colli has been supported by the Thoracic Surgery Foundation for Research and Education/Edwards Lifesciences New and Emerging Technology Fellowship award.

Disclosures: Authors have nothing to disclose with regard to commercial support. Received for publication Feb 12, 2011; revisions received April 5, 2011; accepted for publication April 26, 2011.

Address for reprints: Thomas Walther, MD, PhD, Kerckhoff Heart Center, Department Cardiac Surgery, Benekestr. 2-8 D-61231 Bad Nauheim, Germany (E-mail: t.walther@kerckhoff-klinik.de).

$0022-5223 / \$ 36.00$

Copyright (c) 2011 by The American Association for Thoracic Surgery

doi:10.1016/j.jtcvs.2011.04.026
}

to conventional surgical aortic valve replacement. ${ }^{8,9}$ In contrast with surgery, TAVI does not involve excision of the diseased native valve or annular tissue. The metal stent of the implanted device leads to compression of native valve cusps and associated calcification against the aortic annulus and aortic wall. Paravalvular leak around the valve stent is known to occur in a significant proportion of patients undergoing TAVI, but the precise mechanism behind this phenomenon remains unclear. Paravalvular leak may be related to specific anatomy (in particular, a noncylindric shape) of the annulus or aortic root, or to the amount and distribution of leaflet and annular calcification. Transthoracic echocardiography (TTE) is routinely used for the diagnosis of AS and for postoperative functional assessment after valve surgery. Transesophageal echocardiography (TEE) is frequently used for the preoperative screening of patients undergoing TAVI and during the procedures to assess valve and ventricular function. The routine use of TEE may permit a systematic preoperative analysis of the anatomy of the aortic valve and root, and in particular may allow for better characterization of aortic valve calcification. Improved characterization of aortic 


$$
\begin{aligned}
& \text { Abbreviations and Acronyms } \\
& \text { AR }=\text { aortic regurgitation } \\
& \text { AS }=\text { aortic stenosis } \\
& \text { ECS }=\text { echocardiographic calcification score } \\
& \text { SD }=\text { standard deviation } \\
& \text { TAVI }=\text { transcatheter aortic valve implantation } \\
& \text { TEE }=\text { transesophageal echocardiography } \\
& \text { TTE }=\text { transthoracic echocardiography }
\end{aligned}
$$

valve calcification may allow a better assessment of the risk of developing post-intervention aortic regurgitation (AR).

The current study was designed to investigate the performance of a new echocardiographic calcium score in predicting the occurrence of postoperative AR after TAVI.

\section{MATERIALS AND METHODS Patients}

The clinical charts of 212 consecutive patients who underwent transapical TAVI using a SAPIEN prosthesis (Edwards Lifesciences, Irvine, Calif) at the Leipzig Heart Center between February 2006 and February 2009 were retrospectively identified and reviewed. ${ }^{10}$

The first 50 patients of the series were excluded from the present analysis because they were considered to be part of the early phase of the surgical and technical learning curve. Another 55 patients were excluded because of the absence of high-quality digitalized preoperative TEE and postoperative TTE examinations. Patients who underwent a valvein-valve procedure for severe post-implantation $\operatorname{AR}(n=4)$ were also excluded from the analysis because they were considered as a technical failure with an incorrect level of depth implantation. Thus, a total of 103 patients who received a theoretically well-positioned aortic valve prosthesis $(40 \%-50 \%$ of the valve stent above and $60 \%-50 \%$ below the aortic annulus as recommended by the manufacturer) were included in the present study.

\section{Echocardiographic Assessment}

Since January 2008, TEE has been used routinely for preoperative screening and images stored digitally for all patients. The additional use of TEE for preoperative screening was considered necessary to better understand the morphology of the calcified aortic valve and to precisely measure the aortic valve annulus. Patients with good quality and digitally stored TEE images were included in this study. Echocardiographic studies were considered good when the 3 aortic leaflets and the aortic commissures were clearly identified on examination. TEE examinations were performed using a Vivid 7 machine (General Electric, Milwaukee, Wis), and the images were stored and archived in digital format. Offline image analysis and measurements were carried out using a digital archiving and reporting system (EchoPAC 08, General Electric). Standard TEE examinations were performed with special attention being paid to the aortic annulus, sinotubular junction, distribution and severity of valve calcification, and mitral annulus calcification. Transaortic pressure gradients, aortic valve area, and valvular regurgitation were determined according to published guidelines. ${ }^{11}$

Measurements of the aortic annulus and aortic leaflets were performed using 2-dimensional imaging in long-axis ( $\sim 120-130$ degrees) and shortaxis ( $\sim 45-60$ degrees) views, both in end diastole (defined as the beginning of the QRS). Complete postoperative TTE examination was performed on all patients within 1 week after device implantation. AR was assessed using color Doppler, pressure half-time, vena contracta width, and flow reversal techniques. The AR was classified as paravalvular, transvalvular, or both by using the assessment scheme used by Moss and colleagues ${ }^{12}$ and Kapur and colleagues. $^{13}$

\section{Calcification Score Index}

Corciu and colleagues ${ }^{14}$ described and validated the calcification score index, a semiquantitative echocardiographic cardiovascular score using relatively simple transthoracic echocardiographic parameters (anterior mitral annular calcification, aortic valve sclerosis, and aortic root sclerosis) permitting better characterization of the risk of developing cardiovascular disease. We modified this score and added information on calcification of specific structures of the aortic root (ie, aortic annulus, sinotubular junction, and aortic valve commissures) that we considered potentially important to assess the risk of postoperative AR after TAVI (Table 1).

The independent components of the resultant calcification scoring system were then analyzed univariately for possible associations with the development of postoperative paravalvular AR and transvalvular AR. Those variables with a $P$ value less than .10 were then identified and analyzed. The variables identified were the aortic commissures and the 3 aortic valve cusps: right coronary cusp, left coronary cusp, and noncoronary cusp.

AR was dichotomized into group A (none or trivial/mild) and group B (moderate). The dichotomization was deemed clinically appropriate because trivial/mild regurgitation is considered to be a benign and nonprogressive process in the majority of patients. ${ }^{15}$ The results of the calcification score index variables and new variables added are given in Table 2.

The results of the statistical univariate analyses are presented in Tables 3 and 4.The sum of calcification scores obtained from the 3 aortic cusps and commissures (those variables that were demonstrated to have a univariate association with development of post-TAVI AR) was called the TAVI echocardiographic calcification score (ECS). The TAVI ECS ranged from 0 (normal native aortic valve) to 8 (diffuse calcification of all 3 aortic cusps and commissures). Illustrative examples of echocardiographic images are shown in Figure 1.

We also considered the grade of prosthesis oversizing as a potential variable affecting the presence of postimplantation AR. Oversizing was calculated as the difference between the diameter of the prosthesis implanted (ie, 23 or $26 \mathrm{~mm}$ ) and the annulus size as measured by TEE using 2-dimensional imaging in a long-axis view ( $\sim 120-130$ degrees). Oversizing was further classified into absent ( 0 and $1 \mathrm{~mm}$ ), normal ( 2 and $3 \mathrm{~mm}$ ), and excessive $(>3 \mathrm{~mm})$, and tested for the presence of paravalvular AR and transvalvular AR. The results of this analysis are shown in Tables 3 and 4.

\section{Statistical Analysis}

Patient characteristics were summarized using percentages when the variables were categoric and as mean or median values when the variables were continuous. The Mann-Whitney test was used to compare continuous variables, and the Fisher exact test was used for binary variables. Logistic regression analysis was used to assess the associations between the presence of a postoperative paravalvular AR or transvalvular AR and the variables of the calcification score. Odds ratio and corresponding $95 \%$ confidence intervals were estimated. The inter- and intraobserver reproducibility of TAVI ECS were evaluated using Bland-Altman analysis by calculating the bias (mean difference) and the $95 \%$ limits of agreement ( 2 standard deviation [SDs] around the mean difference).

\section{RESULTS \\ Study Population}

The median age of patients was $82.2 \pm 5.9$ years (range 64.3-97.5 years), and 55 of 103 patients (53.4\%) were female. The mean logistic European System for Cardiac Operative Risk Evaluation was $33.0 \% \pm 16.3 \%$. TEE mean 
TABLE 1. Characteristics of the original variables of the calcification score index and the new variables added (modified from 20)

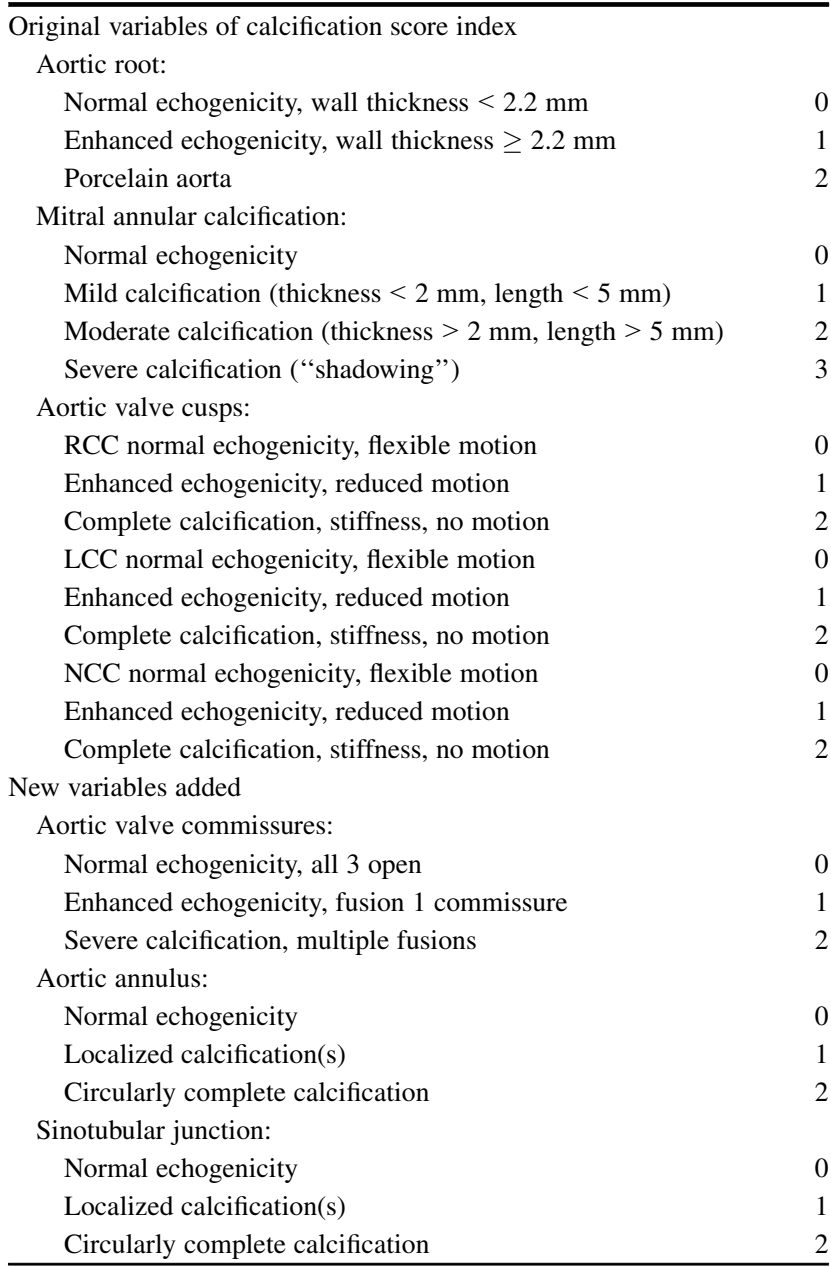

$C S I$, calcification score index; $R C C$, right coronary cusp; $L C C$, left coronary cusp; $N C C$, noncoronary cusp.

aortic annulus dimension during end diastole was $22.5 \pm$ $1.5 \mathrm{~mm}$ (range, $18-26 \mathrm{~mm}$ ). Preoperatively, the mean aortic valve area was $0.5 \pm 0.2 \mathrm{~cm}^{2}$ (range, $0.2-1.1 \mathrm{~cm}^{2}$ ), the mean left ventricular ejection fraction was $54.9 \% \pm 11.2 \%$, the mean peak aortic valve gradient was $72.6 \pm 2.5 \mathrm{~mm} \mathrm{Hg}$, and the mean average aortic valve gradient was $47.2 \pm$ $19.9 \mathrm{~mm} \mathrm{Hg}$. The mean calcification score index with the new variables added for aortic valve was $10.1 \pm 2.7$ (range, 1-16). Scores for individual characteristics of the valve and aortic root are listed in Table 2. Scores 10, 9, and 12 were the most frequent and were present in 18 patients $(17.5 \%), 16$ patients $(15.5 \%)$, and 16 patients $(15.5 \%)$, respectively.

\section{Postimplantation Prosthetic Valve Assessment}

A total of 27 patients $(26.2 \%)$ received a $23-\mathrm{mm} \mathrm{SA}$ PIEN prosthesis, and 76 patients $(73.8 \%)$ received a $26-$ $\mathrm{mm}$ SAPIEN prosthesis. Seven patients $(6.9 \%)$ were found to have isolated central AR post-procedure. Paravalvular
TABLE 2. Results of the calcification score index variables and new variables added

Calcification score index variables and new variables added Patients $(\%)$

Aortic root

0

$7(6.80)$

1

$78(75.73)$

2

$18(17.48)$

Aortic annulus

0

$10(9.71)$

$70(67.96)$

2

$23(22.33)$

$\mathrm{RCC}$

0

$5(4.85)$

$56(54.37)$

$42(40.78)$

LCC

$0 \quad 6(5.83)$

$1256(54.37)$

$2 \quad 41(39.81)$

NCC

$0 \quad 4(3.88)$

$1 \quad 31(30.10)$

$2 \quad 68(66.02)$

Aortic commissure

$\begin{array}{ll}0 & 8(7.77)\end{array}$

$1 \quad 50(48.54)$

$2 \quad 45(43.69)$

MAC

$\begin{array}{ll}0 & 21(20.39)\end{array}$

$1 \quad 58(56.31)$

224 (23.3)

Sinotubular junction

$3(2.91)$

81 (78.64)

$19(18.45)$

2

$10.09 \pm 2.69$

Mean "new" CSI \pm SD

$R C C$, Right coronary cusp; $L C C$, left coronary cusp; $N C C$, noncoronary cusp; $M A C$
mitral annular calcification; $C S I$, calcification score index; $S D$, standard deviation.

AR was absent in 55 patients (53\%), a mild paravalvular leak was present in 43 patients $(42 \%)$, and a moderate paravalvular leak was observed in 5 patients $(5 \%)$. The overall grade of AR was similarly distributed with $50 \%$ of patients exhibiting no regurgitation, $43 \%$ of patients with mild AR, and $7 \%$ of patients with moderate AR. The postoperative mean aortic valve gradient was $8.5 \pm 3.1 \mathrm{~mm} \mathrm{Hg}$, and the mean peak aortic valve gradient was $15.9 \pm 5.3 \mathrm{~mm} \mathrm{Hg}$.

\section{Transcatheter Aortic Valve Implantation Echocardiographic Calcification Score}

In the study population, the TAVI ECS ranged from 1 to 8. A TAVI ECS of 6, 7, or 8 was the most frequent and present in 20 patients for each score value $(19.4 \%$ each). A total of 16 patients $(15.5 \%)$ had a score of 4,15 patients $(14.6 \%)$ had a score of 5,6 patients $(5.8 \%)$ had a score of 3,4 
TABLE 3. Univariate association among calcification score index, new variables added, and prosthesis oversizing with paravalvularaortic regurgitation

\begin{tabular}{cccccc}
\hline Variables & $\begin{array}{l}\text { No. of patients } \\
\text { with AR/N (\%) }\end{array}$ & OR & $95 \%$ CI & P \\
\hline
\end{tabular}

Aortic root

$\begin{array}{ccccc}0 & 0 / 7(0) & \text { Reference } & & .95 \\ 1 & 5 / 78(6.4) & \text { Reference } & & \\ 2 & 1 / 18(5.5) & 0.94 & 0.10-8.58 & \\ \text { Aortic annulus } & & & & \end{array}$

Aortic annulus

\begin{tabular}{|c|c|c|c|c|}
\hline 0 & $1 / 10(10)$ & Reference & & .19 \\
\hline 1 & $2 / 70(2.9)$ & 0.26 & $0.22-3.22$ & \\
\hline 2 & $3 / 23(13)$ & 1.35 & $0.12-14.82$ & \\
\hline \multicolumn{5}{|l|}{$\mathrm{RCC}$} \\
\hline 0 & $0 / 5(0)$ & Reference & & \\
\hline 1 & $0 / 56(0)$ & Reference & & \\
\hline 2 & $6 / 42(14.3)$ & 13.31 & $1.8-\infty$ & .00 \\
\hline \multicolumn{5}{|l|}{ LCC } \\
\hline 0 & $0 / 6(0)$ & Reference & & .02 \\
\hline 1 & $1 / 56(1.8)$ & Reference & & \\
\hline 2 & $5 / 41(12.2)$ & 8.47 & $0.95-75.41$ & \\
\hline \multicolumn{5}{|l|}{$\mathrm{NCC}$} \\
\hline 0 & 0/4 (0) & Reference & & \\
\hline 1 & $0 / 31(0)$ & Reference & & \\
\hline 2 & $6 / 68(8.8)$ & 4.48 & $0.62-\infty$ & .09 \\
\hline \multicolumn{5}{|c|}{ Aortic commissure } \\
\hline 0 & 0/8 (0) & Reference & & .005 \\
\hline 1 & $0 / 50(0)$ & Reference & & \\
\hline 2 & $6 / 45(13.3)$ & 11.71 & $1.63-\infty$ & \\
\hline \multicolumn{5}{|l|}{ MAC } \\
\hline 0 & $1 / 21(4.8)$ & Reference & & .32 \\
\hline 1 & $5 / 58(8.6)$ & 1.87 & $0.19-93.64$ & \\
\hline 2 & $0 / 24(0)$ & 0.875 & $0.01-34.13$ & \\
\hline \multicolumn{5}{|l|}{ STJ } \\
\hline 0 & $0 / 3$ & Reference & & .36 \\
\hline 1 & 4/81 (4.9) & Reference & & \\
\hline 2 & 2/19 (10.5) & 2.35 & $0.39-13.90$ & \\
\hline \multicolumn{5}{|l|}{ PHV oversize } \\
\hline Normal & $2 / 63(3.2)$ & Reference & & .33 \\
\hline Absent & $2 / 16(12.5)$ & 4.36 & $0.56-33.65$ & \\
\hline Excessive & $2 / 24(8.3)$ & 2.77 & $0.36-20.89$ & \\
\hline
\end{tabular}

AR results were dichotomized into group A (none or trivial/mild) and group B (moderate). $A R$, Aortic regurgitation; $O R$, odds ratio; $C I$, confidence interval; $M A C$, mitral annular calcification; $S T J$, sinotubular junction; $P H V$, prosthetic heart valve; $R C C$, right coronary cusp; $L C C$, left coronary cusp; $N C C$, noncoronary cusp.

patients $(3.9 \%)$ had a score of 1,2 patients $(1.9 \%)$ had a score of 2 , and no patient had a score of 0 . The TAVI ECS correlated significantly with the presence of moderate paravalvular AR. The TAVI ECS was not significantly correlated with the presence of transvalvular AR (Table 5).

\section{Oversizing of the Implanted Prosthesis}

The mean amount of prosthesis oversizing was $2.6 \pm 1.2$ $\mathrm{mm}$. An oversizing of 2 and $3 \mathrm{~mm}$ was the most frequently observed, occurring in 32 patients $(31 \%)$ and 31 patients $(30 \%)$, respectively. We failed to find any statistically significant correlation between the amount of oversizing and
TABLE 4. Univariate association among calcification score index, new variables added, and prosthesis oversizing with transvalvular aortic regurgitation

\begin{tabular}{|c|c|c|c|c|}
\hline Variables & $\begin{array}{l}\text { No. of patients } \\
\text { with } A R / N(\%)\end{array}$ & OR & $95 \% \mathrm{CI}$ & $\mathbf{P}$ \\
\hline \multicolumn{5}{|l|}{ Aortic root } \\
\hline 0 & $0 / 7(0)$ & Reference & & \\
\hline 1 & $5 / 78(6.4)$ & Reference & & .45 \\
\hline 2 & 2/18 (11.1) & 2 & $0.34-11.23$ & \\
\hline \multicolumn{5}{|l|}{ Aortic annulus } \\
\hline 0 & $0 / 10(0)$ & Reference & & \\
\hline 1 & $5 / 70(7.1)$ & Reference & & .68 \\
\hline 2 & $2 / 23(8.7)$ & 1.43 & $0.26-7.9$ & \\
\hline \multicolumn{5}{|l|}{$\mathrm{RCC}$} \\
\hline 0 & $1 / 5(20)$ & Reference & & \\
\hline 1 & $3 / 56(5.4)$ & 0.23 & $0.02-2.71$ & .56 \\
\hline 2 & $3 / 42(7.2)$ & 0.31 & $0.03-3.70$ & \\
\hline \multicolumn{5}{|l|}{ LCC } \\
\hline 0 & $1 / 6(16.7)$ & Reference & & \\
\hline 1 & $2 / 56(3.6)$ & 0.19 & $0.01-2.42$ & \\
\hline 2 & 4/41 (9.8) & 0.54 & $0.05-5.85$ & .32 \\
\hline \multicolumn{5}{|l|}{$\mathrm{NCC}$} \\
\hline 0 & $0 / 4(0)$ & Reference & & \\
\hline 1 & $1 / 31(3.2)$ & Reference & & \\
\hline 2 & $6 / 68(8.8)$ & 3.29 & $0.38-28.47$ & .22 \\
\hline \multicolumn{5}{|c|}{ Aortic commissure } \\
\hline 0 & $1 / 8(13)$ & Reference & & \\
\hline 1 & $1 / 50(2)$ & 0.14 & $0.01-2.55$ & .14 \\
\hline 2 & $5 / 45(11.1)$ & 0.88 & $0.09-8.66$ & \\
\hline \multicolumn{5}{|l|}{ MAC } \\
\hline 0 & $3 / 21(14.3)$ & Reference & & \\
\hline 1 & $3 / 58(5.2)$ & 0.33 & $0.06-1.77$ & \\
\hline 2 & $1 / 24(4.2)$ & 0.26 & $0.02-2.72$ & .36 \\
\hline \multicolumn{5}{|l|}{ STJ } \\
\hline 0 & $0 / 3(0)$ & Reference & & \\
\hline 1 & $5 / 81(6.2)$ & Reference & & \\
\hline 2 & 2/19 (10.5) & 1.86 & $0.33-10.40$ & .49 \\
\hline \multicolumn{5}{|l|}{ PHV oversize } \\
\hline Normal & $5 / 63(7.9)$ & Reference & & \\
\hline Absent & $1 / 16(6.3)$ & 0.77 & $0.08-7.13$ & \\
\hline Excessive & $1 / 24(4.2)$ & 0.50 & $0.06-4.55$ & .8 \\
\hline
\end{tabular}

AR results were dichotomized into group A (none or trivial/mild) and group B (moderate). $A R$, Aortic regurgitation; $O R$, odds ratio; $C I$, confidence interval; $M A C$, mitral annular calcification; STJ, sinotubular junction; $P H V$, prosthetic heart valve; $R C C$, right coronary cusp; $L C C$, left coronary cusp; $N C C$, noncoronary cusp.

the development of post-procedure paravalvular and transvalvular AR (Figure 2).

The Bland-Altman analysis of TAVI ECS revealed a nonsignificant bias in interobserver $(0.2$ [ $2 \mathrm{SD},-1.1$ to 1.5$])$ and intraobserver ( 0.4 [2 SD, -1.0 to 1.8$]$ ) measurements. The Bland-Altman analysis for TAVI ESS also resulted in a nonsignificant bias in interobserver ( 0.3 [ $2 \mathrm{SD},-1.2$ to 1.7$])$ and intraobserver ( 0.4 [ $2 \mathrm{SD},-1.0$ to 1.8$])$ measurements.

\section{DISCUSSION}

TAVI has been introduced as an alternative approach to the surgical treatment of patients with AS and high 


\begin{tabular}{|c|c|c|}
\hline $\begin{array}{c}\text { Score Values for } \\
\text { variables: } \\
\text { RCC, LCC,NCC, } \\
\text { Aortic } \\
\text { Commissure }\end{array}$ & Reference Image & Schematic Draw \\
\hline
\end{tabular}

$2,2,2,1$
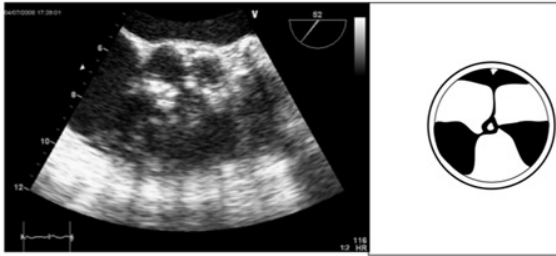

$0,0,1,1$

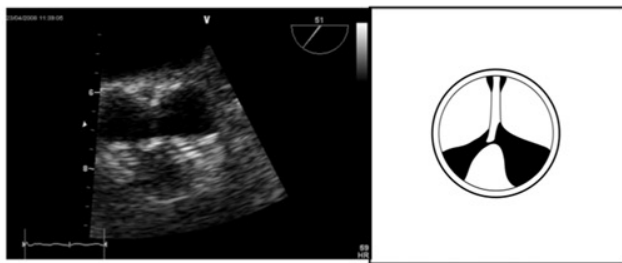

A

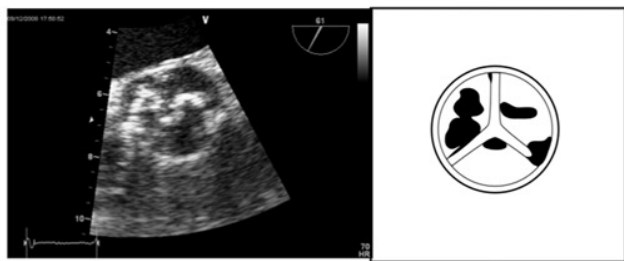

$1,1,1,1$

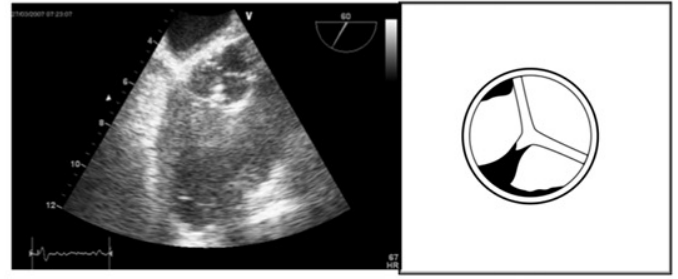

$1,2,2,1$

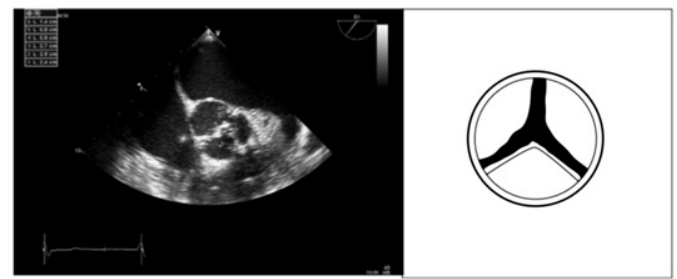

$1,1,2,1$

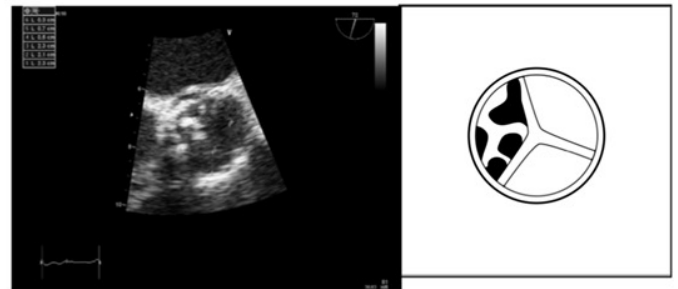

2, 1, 2, 2
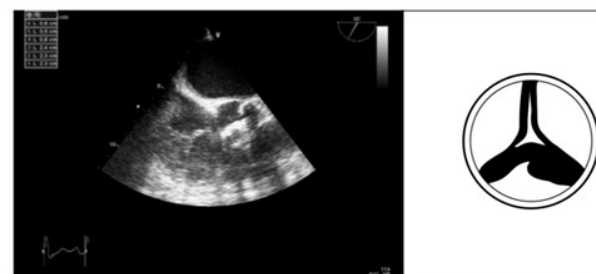

B

$(P=.0057)$. This finding is in accordance with our initial hypothesis that the presence of calcification at the level of the aortic commissures does not permit the stent of the prosthetic valve to reach a complete alignment with the aortic wall, which may lead to the presence of postoperative paravalvular leaks. The results of the present study also indicate a significant correlation between a high TAVI ECS and the presence of moderate paravalvular AR $(P=.0001)$. The presence of bulky calcification at the level of the commissures and leaflet cusps probably prevents adequate alignment of the metal stent against the aortic wall, with a resultant defective seal between these structures.

The present results suggest that the use of the TAVI ECS, as well as the aortic commissure calcification score alone, can predict the development of moderate postoperative paravalvular AR. Another important observation is the fact that oversizing by 2 to $3 \mathrm{~mm}$ was associated with less paravalvular and transvalvular AR when compared with smaller or higher degrees of oversizing (Figure 2). Such a finding is 


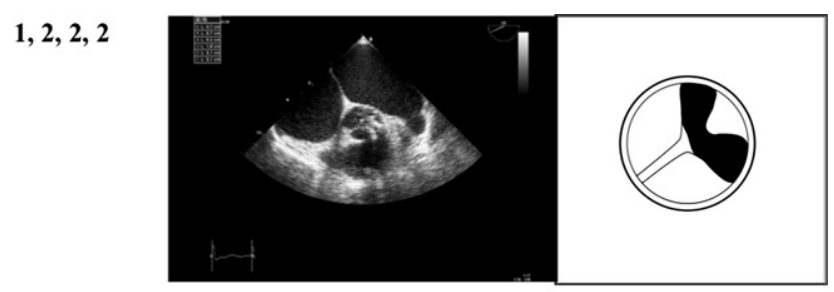

$1,0,0,0$

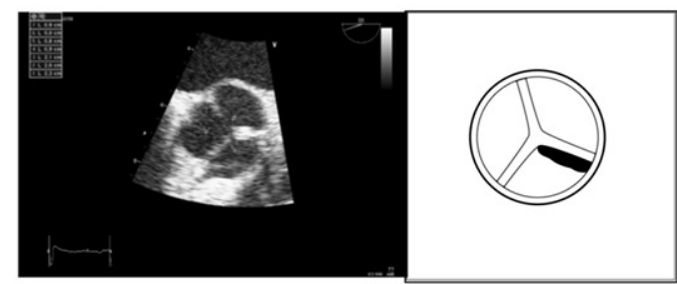

$\mathbf{0 , 0 , 2 , 0}$

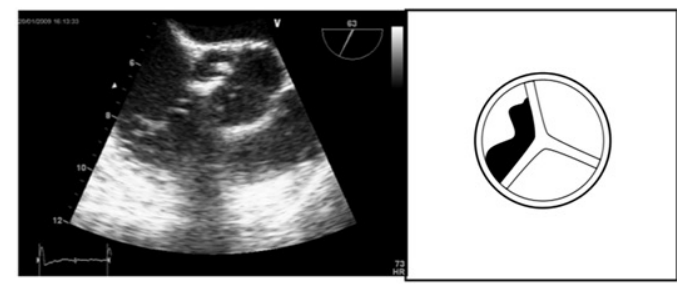

2, 2, 2, 2
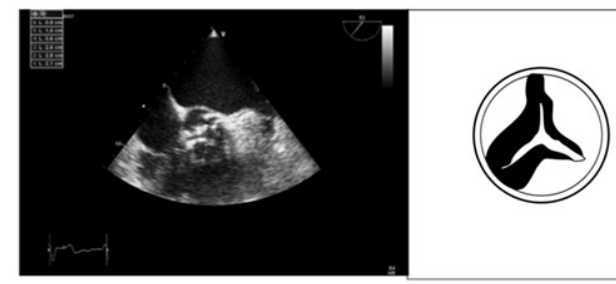

$2,2,2,2$


$2,2,2,2$

C
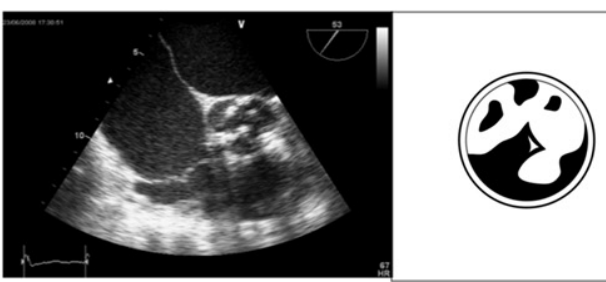

FIGURE 1. (continued).

particularly important because it implies that a wider range of sizes for the SAPIEN prosthesis, as well as for all other potential transcatheter heart valves, should be available for clinical implementation.

We also observed that excessive oversizing was associated with a greater number of patients presenting with triv$\mathrm{ial} /$ mild transvalvular AR. This finding could be explained
TABLE 5. Univariate association among transcatheter aortic valve implantation echocardiographic calcification score, paravalvular aortic regurgitation, and transvalvular aortic regurgitation

\begin{tabular}{lllll}
\hline & Variables & OR & $\mathbf{9 5} \%$ CI & \multicolumn{1}{c}{ P } \\
\hline Paravalvular AR & TAVI ECS & 8.5 & $1.2-58.9$ & .0001 \\
Transvalvular AR & TAVI ECS & 1.2 & $0.7-1.8$ & .48 \\
\hline$O R$, Od
\end{tabular}

$O R$, Odds ratio; $C I$, confidence interval; $A R$, aortic regurgitation; $T A V I$, transcatheter aortic valve implantation; $E C S$, echocardiographic calcification score.

by the fact that overexpansion of the stent may lead to decreased leaflet coaptation, which in turn leads to central valvular incompetence. From a clinical standpoint, it is important to mention that the observed central regurgitation was not clinically relevant in any patient and that it later resolved during follow-up echocardiography in the majority of patients.

We agree with Moss and colleagues ${ }^{12}$ that difficulties observed in accurately assessing paravalvular AR with standard echocardiographic methods remain a clinical challenge. In contrast with these authors, however, we reported our results in terms of none, trivial/mild, or moderate paravalvular AR because we strongly believe that this issue needs to be more fully addressed. Because TAVI has become a clinical reality in a large number of cardiac centers, more thorough comparison with the gold standard (ie, the conventional aortic valve replacement surgery) will be required, and the issue of paravalvular leakage will need to be more fully addressed. ${ }^{17}$

On the basis of the experience of conventional aortic valve surgery, it seems unlikely that trivial or mild degrees of AR will translate into major clinical issues, at least in the early postoperative period. In our study, $53 \%$ of patients presented without any paravalvular leak, $42 \%$ of patients presented with trivial/mild $\mathrm{AR}$, and $5 \%$ of patients

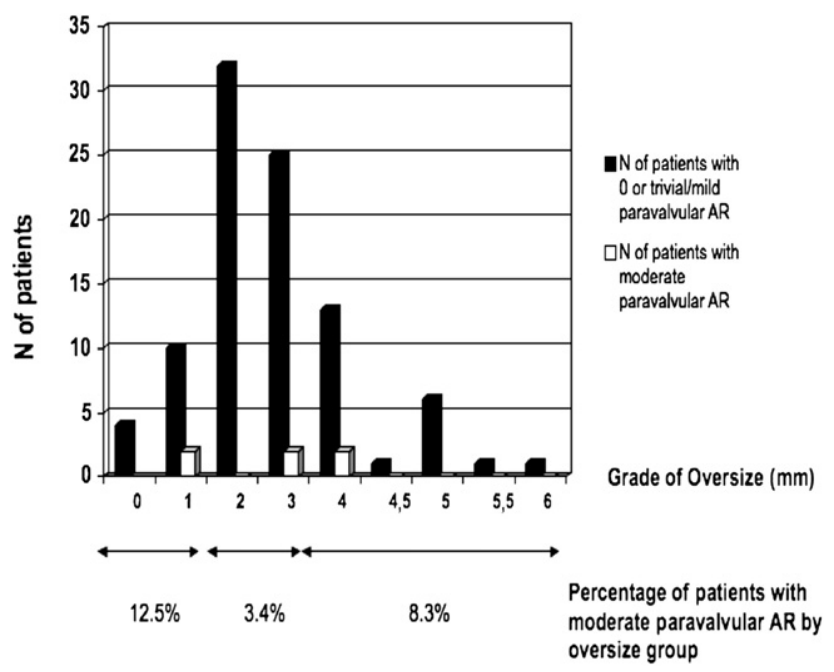

FIGURE 2. Distribution of patients with trivial/mild and moderate paravalvular leak by amount of prosthetic valve oversizing (absent: 0 and $1 \mathrm{~mm}$; normal: 2 and $3 \mathrm{~mm}$; excessive: $>3 \mathrm{~mm}$ ). $A R$, Aortic regurgitation. 
presented with moderate AR, comparing favorably with the literature. $^{12,15,18}$

We believe the clinical results of TAVI are promising. However, the presence of paravalvular AR is frequent, and larger studies with a longer follow-up are needed to determine the progression and significance of paravalvular AR. We agree with Clavel and colleagues ${ }^{18}$ that the uncertainty about paravalvular AR progression and prosthesis durability will play a more prominent role as these therapies are offered to progressively younger patients. The acceptance of paravalvular leakage post-TAVI may result in another "paradigm shift" in valvular therapy. ${ }^{19}$ Newer generation transcatheter prostheses will need to focus on this issue, however, especially if younger patients are to be considered for therapy. ${ }^{19}$

\section{Limitations}

First, the present study is limited by the relatively small sample size of 103 patients leading to some statistical limitations.

Second, the association between TAVI ECS and postintervention AR was tested only in patients undergoing transapical TAVI with a SAPIEN valve, and we do not know the applicability of this scoring system to other delivery access methods (transfemoral or trans-subclavian valve implantation) or other devices.

Third, as demonstrated by $\mathrm{Ng}$ and colleagues, ${ }^{20}$ preoperative 2- and 3-dimensional TEE examinations underestimate the annular/left ventricular outflow tract geometries with respect to the planimetry areas calculated with multislice computed tomography.

Fourth, the use of 2-dimensional echocardiography for the assessment of cusps and commissures calcifications may be limited by insufficient imaging or difficulties achieving an appropriate parallel plane to the aortic annulus (the nadirs of the aortic sinuses lie in a plane tilted 30 degrees from the horizontal).

Fifth, the echocardiography-based calcium scoring system has not been cross-validated with multislice computed tomography, which is known to be the gold standard imaging technique to assess and quantify calcium in the aortic valve. $^{21,22}$

\section{CONCLUSIONS}

Calcification of the aortic valve and commissures is associated with the development of post-TAVI AR. The semiquantitative TAVI ECS was found to be a simple and reproducible instrument to evaluate the anatomic structures of the calcified aortic root. TAVI ECS may be used to identify patients at high risk for the development of postintervention AR on the basis of their aortic valve calcification patterns and may therefore aid in future decisionmaking regarding TAVI therapy.

\section{References}

1. Banbury MK, Cosgrove DM 3rd, Thomas JD, Blackstone EH, Rajeswaran J, Okies JE, et al. Hemodynamic stability during 17 years of the Carpentier-Edwards aortic pericardial bioprosthesis. Ann Thorac Surg. 2002;73:1460-5

2. Myken PS, Bech-Hansen O. A 20-year experience of 1712 patients with the Biocor porcine bioprosthesis. J Thorac Cardiovasc Surg. 2009;137:76-81.

3. Borger MA, Ivanov J, Armstrong S, Christie-Hrybinsky D, Feindel CM, David TE. Twenty-year results of the Hancock II bioprosthesis. J Heart Valve Dis. 2006;15:49-55.

4. Chukwuemeka A, Borger MA, Ivanov J, Armstrong S, Feindel CM, David TE. Valve surgery in octogenarians: a safe option with good medium-term results. J Heart Valve Dis. 2006;15:191-6.

5. Kolh P, Kerzmann A, Honore C, Comte L, Limet R. Aortic valve surgery in octogenarians: predictive factors for operative and long term results. Eur J Cardiothorac Surg. 2007;31:600-6.

6. Melby SJ, Zierer A, Kaiser SP, Guthrie TJ, Keune JD, Schuessler RB, et al. Aortic valve replacement in octogenarians. Risk factors for early and late mortality. Ann Thorac Surg. 2007;83:1651-7.

7. Leontyev S, Walther T, Borger MA, Lehmann S, Funkat AK, Rastan A, et al. Aortic valve replacement in octogenarians: utility of risk stratification with EuroSCORE. Ann Thorac Surg. 2009;87:1440-5.

8. Webb JG, Chandavimol M, Thompson CR, Ricci DR, Carere RG, Munt BI, et al Percutaneous aortic valve implantation retrograde from the femoral artery. Circulation. 2006;113:842-50

9. Walther T, Falk V, Borger MA, Dewey T, Wimmer-Greinecker G, Schuler G, et al. Minimally invasive transapical beating heart aortic valve implantationproof of concept. Eur J Cardiothorac. Surg. 2007;31:9-15.

10. Walther T, Dewey T, Borger MA, Kempfert J, Linke A, Becht R, et al. Transapical aortic valve implantation: step by step. Ann Thorac Surg. 2009;87:276-83.

11. Baumgartner H, Hung J, Bermejo J, Chambers JB, Evangelista A, Griffin BP, et al. Echocardiographic Assessment of Valve Stenosis: EAE/ASE Recommendations for Clinical Practice. J Am Soc Echocardiogr. 2009;22:1-23.

12. Moss RR, Ivens E, Pasupati S, Humphries K, Thompson CR, Munt B, et al. Role of echocardiography in percutaneous aortic valve implantation. JACC Cardiovasc Imaging. 2008;1:15-24.

13. Kapur KK, Fan P, Nanda NC, Yoganathan AP, Goyal RG. Doppler color flow mapping in the evaluation of prosthetic mitral and aortic valve function. $J \mathrm{Am}$ Coll Cardiol. 1989;13:1561-71.

14. Corciu AI, Siciliano V, Poggianti E, Petersen C, Venneri L, Picano E. Cardiac calcification by transthoracic echocardiography in patients with known or suspected coronary artery disease. Int J Cardiol. 2010;142:288-95.

15. Ye J, Cheung A, Lichtenstein SV, Altwegg LA, Wong DR, Carere RG, et al. Transapical transcatheter aortic valve implantation: 1-year outcome in 26 patients. J Thorac Cardiovasc Surg. 2009;137:167-73.

16. Bleiziffer S, Ruge H, Mazzitelli D, Schreiber C, Hutter A, Laborde JC, et al. Results of percutaneous and transapical transcatheter aortic valve implantation performed by a surgical team. Eur J Cardiothorac Surg. 2009;35:615-20.

17. Akins CW, Miller DC, Turina MI, Kouchoukos NT, Blackstone EH Grunkemeier GL, et al. STS; AATS; EACTS. Guidelines for reporting mortality and morbidity after cardiac valve interventions. Ann Thorac Surg. 2008;85: 1490-5.

18. Clavel MA, Webb JG, Pibarot P, Altwegg L, Dumont E, Thompson C, et al. Comparison of the Hemodynamic performance of percutaneous and surgical Bioprostheses for the treatment of severe aortic stenosis. J Am Coll Cardiol. 2009;53: 1883-91.

19. Walther T, Falk V. Hemodynamic evaluation of heart valve prostheses: paradigm shift for transcatheter valves? J Am Coll Cardiol. 2009;53:1892-3.

20. Ng AC, Delgado V, van der Kley F, Shanks M, van de Veire NR, Bertini M, et al Comparison of aortic root dimensions and geometries before and after transcatheter aortic valve implantation by 2- and 3-dimensional transesophageal echocardiography and multislice computed tomography. Circ Cardiovasc Imaging 2010;3:94-102.

21. Tops LF, Wood DA, Delgado V, Schuijf JD, Mayo JR, Pasupati S, et al. Noninvasive evaluation of the aortic root with multislice computed tomography implications for transcatheter aortic valve replacement. JACC Cardiovasc Imaging. 2008; 1:321-30.

22. Delgado V, Ng AC, van de Veire NR, van der Kley F, Schuijf JD, Tops LF, et al Transcatheter aortic valve implantation: role of multi-detector row computed tomography to evaluate prosthesis positioning and deployment in relation to valve function. Eur Heart J. 2010;31:1114-23. 